\title{
Changes in expected taste perception of probiotic and conventional yogurts made from goat milk after rapidly repeated exposure
}

\author{
M. P. Costa, ${ }^{\star 1}$ C. F. Balthazar, ${ }^{\star}$ R. M. Franco, ${ }^{*}$ E. T. Mársico, ${ }^{*}$ A. G. Cruz,† and C. A. Conte Junior ${ }^{\star}$ \\ ${ }^{\star}$ Fluminense Federal University, Food Technology Department, CEP 24230-340, Niterói, RJ, Brazil \\ †Master in Food and Science Programe, Instituto Federal de Educação, Ciência e Tecnologia do Rio de Janeiro, CEP 20270-021, Rio de Janeiro, \\ RJ, Brazil
}

\section{ABSTRACT}

Goat milk yogurt is an excellent source of fatty acids, protein, and minerals; however, it is not well accepted by many consumers, due to its typical flavor derived from caprylic, capric, and caproic acids present in this milk and dairy products. Recently, the repeated-exposure test has been used to increase the consumption of particular foods. This methodology has been used to increase children's willingness to eat food in some settings and has also been used to reduce sodium in soup. Based on these considerations, the aim of this study was to investigate whether repeated exposures may increase acceptance of both goat milk yogurt and probiotic goat milk yogurt. In a pre-exposure session, a total of 45 panelists (28 females and 17 males) from southeastern Brazil, who were not used to consuming dairy goat milk, evaluated the expected taste perception and the perceived liking after tasting 3 yogurt preparations. Then, consumers were randomly divided into 3 groups and participated in rapidly repeated exposure sessions performed within 6 d. Each panelist consumed only the yogurt that he or she would be exposed to. The day after the exposure sessions, all panelists returned to participate in the postexposure session and were asked to evaluate acceptance, familiarity, and the "goaty taste" characteristic of each yogurt. Regarding the expected liking before tasting, results showed higher expectations for cow milk yogurt compared with goat milk yogurt, which proved that consumers were not familiar with the goat milk yogurt. Likewise, only cow milk yogurt presented high acceptance and familiarity rates, confirming that these panelists were used to consuming cow milk products. With respect to the rapidly repeated exposure, $6 \mathrm{~d}$ were enough to significantly increase the consumers' familiarity with goat milk yogurt and probiotic goat milk yogurt. However, this method was not suitable to significantly increase the acceptance

\footnotetext{
Received October 16, 2013.

Accepted January 6, 2014.

${ }^{1}$ Corresponding author: marioncosta@id.uff.br or marionpdc@ vm.uff.br
}

of such products. Nonetheless, a correlation existed between the exposure sessions and the increase in acceptance of the exposure groups. Thus, hypothetically, the increasing of exposure sessions could be a strategy to increase goat milk product acceptance.

Key words: caprine milk, Lactobacillus acidophilus, familiarity, acceptance

\section{INTRODUCTION}

Goat milk is an excellent source of FA, protein, and minerals. The importance of goat milk as a functional food is related to its high digestibility and nutritional value, as well as its therapeutic and dietary characteristics (Fonseca et al., 2013). Goat milk fat globules have a smaller size and high proportion of short- and medium-chain SFA, such as butyric, caproic, caprylic, and capric, and long-chain MUFA and PUFA, which are easily absorbed and more digestible than those from cow milk (Park et al., 2007). Moreover, it is hypoallergenic, being commonly consumed by individuals who are allergic to cow milk, such as children and elderly people (Albenzio et al., 2012). For this reason, goat milk is widely used for fermented milk processing and other dairy products. However, its higher caproic, caprylic, and capric acid concentrations, which are responsible for its distinctive taste, make this product not well accepted by consumers (Park et al., 2007; Mayer and Fiechter, 2012). Goat milk yogurt presents a lower overall acceptance compared with cow milk yogurt (Eissa et al., 2010; Masamba and Ali, 2013) because of its unpleasant "goaty" taste, as it is perceived by consumers, even in goat milk yogurt with added fruit pulp (Senaka Ranadheera et al., 2012).

Fermented dairy products, especially yogurt, are commonly used as food vehicles to deliver probiotics to consumers (Wang et al., 2012; da Costa et al., 2013a). Probiotics are live microorganisms, which when consumed in adequate amounts, confer a health benefit on the host (Sanders, 2009). Some health benefits attributed to probiotics include the improvement of intestinal health by regulating the microbiota, immune system stimulation and development, synthesis and enhance- 
ment of the bioavailability of nutrients, reduction of lactose intolerance symptoms, and reduction in the risk of certain diseases (Oelschlaeger, 2010). Taking into consideration the health benefits related to probiotics ingestion, the dairy industry has also invested in probiotic product development because of sensory advantages that bacterial strains confer to the final product (Vinderola et al., 2000; Costa and Conte-Junior, 2013). Lactobacillus acidophilus LA-5 may produce flavor compounds, such as acetaldehyde, which are recognized as important flavor components in yogurt. Lactobacillus acidophilus may increase the total acetaldehyde content in yogurts and, thus, influence the final product flavor (Güler-Akın and Akın, 2007; Ekinci and Gurel, 2008). Moreover, probiotic goat milk yogurt may become more acceptable and sensory appealing to consumers (Senaka Ranadheera et al., 2012).

Expectations play an important role in product perception before it is tasted. These may positively or negatively influence the product flavor (Deliza and MacFie, 1996). The expectations imply a psychological anticipation that something will occur or be experienced. In general terms, we can define an expectation as a belief that an object possesses a particular attribute or that a behavior would result in a particular consequence. Hence, operationally, we might define it in terms of perceived probability or anticipated magnitude for these attributes or consequences (Cardello, 2007). It is possible to analyze whether consumers' expectations are met by the product's actual performance and, otherwise, how the expectations affect consumers' perceived product performance (Cardello and Sawyer, 1992). A product expectation might also influence long-term consumer satisfaction. Hedonic expectations are generated from emotional and cognitive processes, which lead to anticipation of how much the product is liked or disliked before consumption. Ares et al. (2010) obtained a different perception of chocolate desserts, which suggested the importance of consumer expectations on perception and hedonic reaction toward food products. Another study demonstrated that high expectations influenced the liking of local apple juices (Stolzenbach et al., 2013).

Repeated-exposure methodology has been recognized as a useful strategy to increase the overall liking of a certain class of foods in a specific group or in a more general context, for all populations (Williams et al., 2008). This approach has also been used in several different situations in sensory and consumer science. Williams et al. (2008) conducted an experiment with 6 children during 10 to 15 d of exposures. Sixty-three infants or children were repeatedly exposed to a specific food for $8 \mathrm{~d}$ (Liem and Graaf, 2004) and results showed that the exposure method increased liking. Anzman-
Frasca et al. (2012) showed that simple familiarization procedures can be used to promote increased overall acceptance and intake of vegetables among 47 young children. In addition, Lakkakula et al. (2010) used elementary school children to assess the sensory properties of poorly liked vegetables and results showed that $14 \mathrm{~d}$ of repeated exposures to poorly liked vegetables twice per week for a 4 -wk period increased liking for most of these items. Recently, this method has been used with reduced-sodium soups, performed in just 8 exposure days with 37 consumers (Methven et al., 2012), 46 participants (Liem et al., 2012), and sport drinks using 128 consumers (Kinnear and de Kock, 2011).

The aim of this study was to assess expectation of unusual consumers toward goat milk yogurts (probiotic and conventional), and to investigate whether repeated exposures can be used to increase acceptance of this product. The results can be relevant for goat milk industries that intend to gain more consumers for their products.

\section{MATERIALS AND METHODS}

\section{Experimental Design}

The experimental design for this study is represented in Figure 1. For this experiment, 45 participants were selected. First, in the pre-exposure session, participants underwent an expected taste perception, in which the expectation of yogurts was evaluated. Afterwards, participants received, individually, each yogurt (cow, goat, and goat probiotic yogurt) and analyzed the perceived liking after tasting. In the following step, the participants were divided into 3 groups: (1) cow milk yogurt (control, CNTL), (2) goat milk yogurt (exposure group 1, EXP1), and (3) probiotic goat milk yogurt (exposure group 2, EXP2). Participants had to consume the product for 6 consecutive days, evaluating the acceptance and familiarity. Finally, the 45 participants returned for a postexposure session when the 3 yogurts were analyzed for characteristic flavor derived from goat products, acceptance, and familiarity.

\section{Yogurt Processing}

To produce the yogurts, $13 \mathrm{~L}$ of UHT cow whole milk (Macuco, Rio de Janeiro, Brazil) and $25 \mathrm{~L}$ of UHT goat whole milk (Caprilat, Paraná, Brazil) were used, as well as sugar $(5 \%, \mathrm{vol} / \mathrm{vol})$, in each yogurt. Thermophilic yogurt cultures (YF-L903; Chr. Hansen, Valinhos, Brazil) were added to cow milk yogurt and goat milk yogurt at a concentration of $1 \%$ ( vol $/ \mathrm{vol})$. Lactobacillus acidophilus LA-5 (Chr. Hansen) was inoculated at a concentration of $5 \%(\mathrm{vol} / \mathrm{vol})$ in relation 


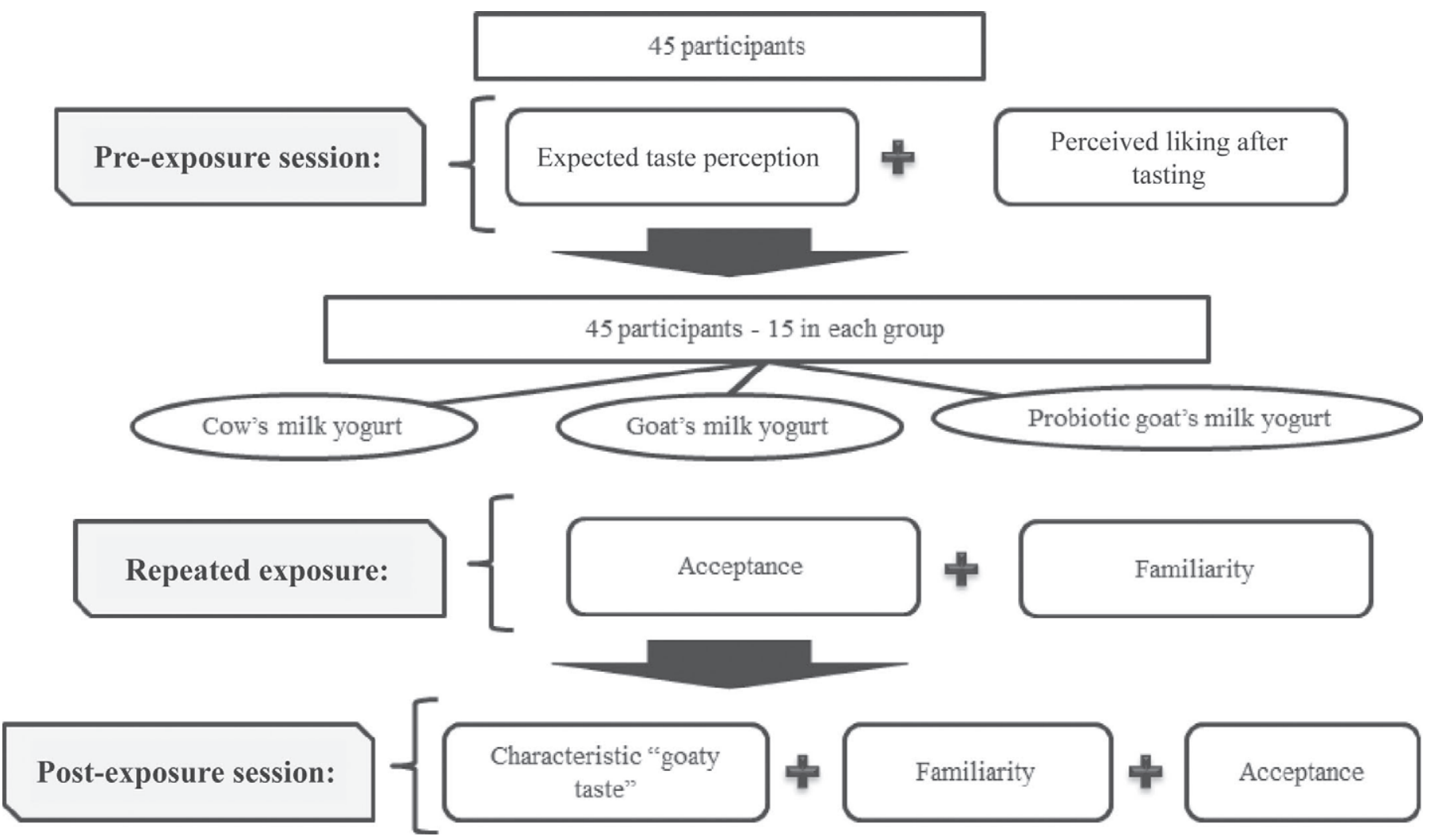

Figure 1. Schematic experimental procedure illustrating the steps involved in the study.

to the total milk volume used to produce the probiotic goat milk yogurt. Then, thermophilic yogurt culture YF-L903 1\% (vol/vol) was also added to the mixture. Samples were fermented in the oven at $40 \pm 2^{\circ} \mathrm{C}$ for $8 \mathrm{~h}$, and fermentation was interrupted when the $\mathrm{pH}(\mathrm{AOAC}$ International, 2005) reached 4.5. Finally, the product was packaged in 500-mL plastic pots and stored at $4 \pm$ $2^{\circ} \mathrm{C}$ for $1 \mathrm{~d}$, until use.

\section{Bacterial Analysis}

Streptococcus thermophilus enumeration was performed on M17 agar, and the count of Lactobacillus delbrueckii ssp. bulgaricus was performed on de Man, Rogosa, and Sharpe (MRS) agar, according to the procedures outlined by the Codex Alimentarius standard for fermented milk to characterize the fermented product as yogurt (Codex Alimentarius, 2010). Enumeration of Lb. acidophilus LA-5 was performed on MRS agar supplemented with $0.15 \%$ ( $\mathrm{vol} / \mathrm{vol}$ ) bile salts at $37^{\circ} \mathrm{C}$ for $72 \mathrm{~h}$ under aerobic conditions, as described elsewhere (Cruz et al., 2012, 2013b). These analyses were carried out because a specified minimum concentration exists, namely 6 to $7 \log$, to classify the product as a probiotic (Bedani et al., 2013). All bacterial counts were performed in triplicate.

\section{Sensory Evaluation}

For the sensory evaluation, the participants were recruited from the Fluminense Federal University (Niterói, RJ, Brazil). The consumers who did not regularly eat yogurt (i.e., at least once per week), did not like yogurt, or had allergies related to any of the ingredients used in the experiment were excluded from the sensory test. A total of 45 panelists ranging from 20 to $60 \mathrm{yr}$ old ( 28 females: mean age $=48.3 \pm 13.6$ yr; 17 males: mean age $=44.5 \pm 15.2 \mathrm{yr}$ ) participated in the study. Pahelist sex and age were not related to any outcome variables.

\section{Pre-Exposure Session}

Expected Taste Perception. This methodology was adapted from Liem et al. (2012). During a preexposure session, consumers were asked to rate their expectations based on their opinion for good yogurt flavor. At this stage, participants had no previous contact with the product. To assess expectations concerning acceptance and familiarity with goat milk yogurt and cow milk yogurt, panelists answered 3 questions about each treatment: (1) expected acceptance: "What is your expected taste for this sample?" (2) expected familiar- 
ity: "Do you expect to be familiar with this product?" and (3) taste desire: "How much do you like the typical flavor of goat milk products?" The responses were measured on a 9 -point scale, where 9 is the best score and 1 is the worst.

Perceived Liking After Tasting. This methodology was adapted from Liem et al. (2012). After the initial questionnaire was filled out, the participants individually tasted each yogurt. The sensory analysis was performed in individual booths, and the 3 samples (20 mL) were coded with 3 -digit codes and presented monadically, using a randomized complete block design (MacFie et al., 1989). The participants were asked to classify how the product actually tasted (hereafter referred to as "actual" taste). The main outcome variables were sample acceptance and familiarity, based on a 9-point hedonic scale: like extremely/extremely familiar $=9$, like very much/very familiar $=8$, like moderately/moderately familiar $=7$, like slightly $/$ slightly familiar $=6$, neither like nor dislike/neither familiar nor unfamiliar $=5$, dislike slightly/slightly unfamiliar $=4$, dislike moderately / moderately unfamiliar $=3$, dislike very much/very unfamiliar $=2$, and dislike extremely/extremely unfamiliar $=1$.

Subsequently, panelists were randomly divided into 3 exposure groups, containing 15 individuals each. Over the next 6 successive working days (exposures 1-6), all groups received samples of $700 \mathrm{~mL}$ of cow milk yogurt (CNTL), goat milk yogurt (EXP1), or probiotic goat milk yogurt (EXP2), depending on the group to which each consumer was assigned.

\section{Repeated-Exposure Sessions}

This methodology was adapted from Methven et al. (2012). In each exposure session, the EXP1 $(\mathrm{n}=15)$ and EXP2 ( $\mathrm{n}=15)$ groups received goat milk yogurt samples $(100 \mathrm{~mL})$ and probiotic goat milk yogurt samples $(100 \mathrm{~mL})$, respectively, whereas the CNTL group $(\mathrm{n}=15)$ received cow milk yogurt samples $(100 \mathrm{~mL})$. All participants were asked to classify their overall sample acceptance and familiarity on each day of evaluation. Participants were asked to refrain from eating for at least $1 \mathrm{~h}$ before the session and, in all cases, the exposure took place before lunch.

\section{Postexposure Session}

After the exposure sessions, the panelists returned to the laboratory to participate in the final session. The sensory analysis was performed in individual staterooms, and the samples $(20 \mathrm{~mL})$ were coded with 3 -digit codes and presented monadically, using a randomized complete block design (MacFie et al., 1989). After the sixth exposure, all panelists were asked to assess accep- tance, familiarity, and the characteristic "goaty" taste (Slačanac et al., 2010) of each yogurt sample, using a 9-point hedonic scale. The control sample was not evaluated with respect to "goaty" taste.

\section{Statistical Analysis}

The first and final sessions results were subjected to one-way ANOVA, considering the yogurt samples as sources of variation. Exposure-session data were subjected to 2-way ANOVA, considering samples and consumers as sources of variation. When significant differences were observed using ANOVA, means were compared using the Tukey test at $P<0.05$, using XLSTAT software (version 2013.2.03; Addinsoft, Paris, France). The ratings of familiarity of the exposure session were also subjected to Pearson correlation analysis. Data from the final session were analyzed separately for each exposure group, whereas acceptance and familiarity data from 45 panelists were grouped for comparison with the first session.

\section{RESULTS AND DISCUSSION}

\section{Probiotic Viable Count}

After fermentation, the bacteria counts of the cow milk yogurt were 9.27 and $8.25 \mathrm{log} \mathrm{cfu} / \mathrm{g}$, whereas the goat milk yogurt presented 9.31 and $8.20 \mathrm{log} \mathrm{cfu} / \mathrm{g}$ for Strep. thermophilus and Lb. delbrueckii ssp. bulgaricus, respectively. Bacterial counts characterized the fermented milk as yogurt, according to the Codex Alimentarius (2010). For the probiotic goat milk yogurt, these values were 8.99, 7.83, and $9.49 \mathrm{log} \mathrm{cfu} / \mathrm{g}$ for Strep. thermophilus, Lb. delbrueckii ssp. bulgaricus, and Lb. acidophilus, respectively. The Lb. acidophilus count was higher than the minimum required count to confer physiological benefits (Bedani et al., 2013).

Probiotic bacteria addition creates sensory advantages and an expanding variety of dairy products (Vinderola et al., 2000; Gomes et al., 2011; Castro et al., 2013a,b). Besides that, the Lb. acidophilus LA-5 may produce flavor compounds, such as acetaldehyde, which are recognized as important flavor components in yogurt (Güler-Akın and Akın, 2007; Ekinci and Gurel, 2008). Moreover, probiotic goat milk yogurt could become more acceptable and appealing (Senaka Ranadheera et al., 2012). In this study, despite the additional probiotic flavor, no increase in acceptance by consumers was observed (Tables 1 and 2).

\section{Expected Taste Perception and Perceived Liking After Tasting}

The results of expected taste perception and perceived liking of the yogurts are shown in Table 1 . No 
Table 1. Mean expected and perceived liking for yogurts (cow milk yogurt, goat milk yogurt, and probiotic goat milk yogurt)

\begin{tabular}{lcccccc}
\hline & \multicolumn{2}{c}{ Expected liking before tasting } & & \multicolumn{2}{c}{ Perceived liking after tasting } \\
\cline { 2 - 3 } \cline { 6 - 7 } Treatment & Question 1 & Question 2 & Question 3 & & Acceptance & Familiarity \\
\hline Cow milk yogurt & $7.889^{\mathrm{a}}$ & $8.156^{\mathrm{a}}$ & - & & $7.622^{\mathrm{a}}$ & $7.644^{\mathrm{a}}$ \\
Goat milk yogurt & $5.289^{\mathrm{b}}$ & $3.778^{\mathrm{b}}$ & $5.067^{\mathrm{b}}$ & & $5.000^{\mathrm{b}}$ & $4.911^{\mathrm{b}}$ \\
Probiotic goat milk yogurt & $4.956^{\mathrm{b}}$ & $3.200^{\mathrm{b}}$ & $5.089^{\mathrm{b}}$ & & $4.511^{\mathrm{b}}$ & $4.311^{\mathrm{b}}$ \\
\hline
\end{tabular}

$\overline{\mathrm{a}, \mathrm{b}}$ Averages within a column with different superscript letters differ $(P<0.05)$.

${ }^{1}$ Question 1: "What is your expected taste for this sample?"; Question 2: "Do you expect to be familiar with this product?"; Question 3: "How much do you like the typical flavor of goat milk products?"

significant effects of age (20 to $60 \mathrm{yr}$ old) or gender ( 28 females: mean age $=48.3 \pm 13.6 \mathrm{yr} ; 17$ males: mean age $=44.5 \pm 15.2 \mathrm{yr})$ with respect to liking and consumption was observed. As there is lack of information about the application of this type of sensory strategy in dairy products, data were compared with other nondairy matrices, such as juice and soup; in this sense, data from all participants were grouped for all analyses.

In relation to expected liking before tasting, the control group (cow milk yogurt) achieved good scores of 7.889 for question $1(F=31.887 ; P<0.001)$ and 8.156 for question $2(F=32.597 ; P<0.001)$, which can be explained by the high familiarity of consumers with the product. These results are in accordance with Stolzenbach et al. (2013), who obtained high expectations for familiar local apple juices. Question 3, "How much do you like the typical flavor of goat milk products?" did not apply to the CNTL group. The EXP1 and EXP2 groups were indifferent for both questions 1 and 3 , scoring them as "will not like/will not dislike," which proves that the consumers were not familiar with these products (goat milk yogurt and probiotic goat milk yogurt).

The perceived liking of the yogurts evaluated the panelists' acceptance and familiarity with the product. The CNTL group presented high acceptance and familiarity ratings $(F=33.94$ and $P<0.001, F=32.234$ and $P<0.001$, respectively), which confirmed that panelists were used to consuming cow milk yogurt. The same was observed by Methven et al. (2012), who found that high-salt soups were overall more familiar before exposure. In the current study, the acceptance and familiarity ratings of EXP1 and EXP2 groups showed a similar pattern, presenting scores of 4.51 and 5.00, respectively. These data were different from the results found by Ares et al. (2010), who obtained higher overall liking for desserts in which consumers had expected offflavor. In our study, consumers were indifferent to goat products in both expectation and acceptance, maybe due to the initial unfamiliarity with these products. Indeed, there is a low consumption of goat milk products by Brazilian people, as such products are restricted to a selected social class with more financial resources, which can acquire these products in special establishments and some fancy supermarkets.

\section{Repeated Exposure}

The repeated-exposure results are shown in Figures 2 and 3, which exhibit the mean ratings for yogurt acceptance and familiarity, respectively. An increase in acceptance was observed for the EXP1 and EXP2 groups, but not for the CNTL group (Figure 2). Although this increase was not statistically significant $(F$ $=20.261 ; P<0.001$ ), it was not sufficient to render product acceptance. Moreover, both groups, EXP1 (r $=0.99 ; P<0.05)$ and EXP2 $(\mathrm{r}=0.99 ; P<0.05)$

Table 2. Mean scores (separated by each group) for final session acceptance, familiarity, and characteristic "goaty" taste of the yogurts

\begin{tabular}{llccc}
\hline Exposure group & Category & Acceptance & Familiarity & $\begin{array}{c}\text { Characteristic } \\
\text { "goaty" taste }\end{array}$ \\
\hline Cow milk yogurt & Control & $7.467^{\mathrm{a}}$ & $7.933^{\mathrm{a}}$ & - \\
& Exposure 1 & $6.933^{\mathrm{a}}$ & $8.200^{\mathrm{a}}$ & - \\
Goat milk yogurt & Exposure 2 & $7.267^{\mathrm{a}}$ & $7.600^{\mathrm{a}}$ & - \\
& Control & $5.467^{\mathrm{a}}$ & $5.333^{\mathrm{a}}$ & $4.867^{\mathrm{a}}$ \\
& Exposure 1 & $5.267^{\mathrm{a}}$ & $6.867^{\mathrm{a}, \mathrm{b}}$ & $5.000^{\mathrm{a}}$ \\
Probiotic goat milk yogurt & Exposure 2 & $5.733^{\mathrm{a}}$ & $7.533^{\mathrm{b}}$ & $5.533^{\mathrm{a}}$ \\
& Control & $4.867^{\mathrm{a}}$ & $5.267^{\mathrm{a}}$ & $4.267^{\mathrm{a}}$ \\
& Exposure 1 & $5.333^{\mathrm{a}}$ & $6.733^{\mathrm{a}, \mathrm{b}}$ & $5.067^{\mathrm{a}}$ \\
& Exposure 2 & $5.933^{\mathrm{a}}$ & $7.333^{\mathrm{b}}$ & $5.200^{\mathrm{a}}$ \\
\hline
\end{tabular}

$\overline{\mathrm{a}, \mathrm{b}}$ Averages within a column with different superscript letters differ $(P<0.05)$. 
Table 3. Comparison of scores between first and final sessions

\begin{tabular}{lccccc}
\hline & \multicolumn{2}{c}{ Acceptance } & & \multicolumn{2}{c}{ Familiarity } \\
\cline { 2 - 3 } \cline { 5 - 6 } Treatment & First session & Final session & & First session & Final session \\
\hline Cow milk yogurt & $7.622^{\mathrm{a}}$ & $7.222^{\mathrm{a}}$ & & $7.644^{\mathrm{a}}$ & $7.911^{\mathrm{a}}$ \\
Goat milk yogurt & $5.000^{\mathrm{a}}$ & $5.489^{\mathrm{a}}$ & & $4.911^{\mathrm{a}}$ & $6.711^{\mathrm{b}}$ \\
Probiotic goat milk yogurt & $4.511^{\mathrm{a}}$ & $5.377^{\mathrm{a}}$ & & $4.311^{\mathrm{a}}$ & $6.444^{\mathrm{b}}$ \\
\hline a,b A & & & & &
\end{tabular}

presented a positive correlation between acceptance and days of exposure. Thus, it can be assumed that increasing exposure time may increase the acceptance of goat milk yogurts. According to Cardello et al. (2000), food acceptance is determined by the perception and liking of the attributes taste, flavor, and texture. For children, the acceptance of a new product is related to its appearance, taste, and familiarity (Burgess-Champoux et al., 2006). In the current study, some technical modifications in the formulations could also be done to increase the acceptance of goat milk yogurt, such as fruit pulp addition to the product (Senaka Ranadheera et al., 2012).

However, the ratings of familiarity showed a significant increase (Figure 3) for both goat milk yogurts (EXP1 and EXP2 groups). With respect to the first session, this change was evident at the second exposure. A strong positive correlation between familiarity and exposure days was observed for all groups (CNTL $\mathrm{r}$ $=0.98, \mathrm{EXP} 1 \mathrm{r}=0.99$, and EXP2 $\mathrm{r}=0.998$; all $P<$ $0.05)$. Nevertheless, a significant increase in familiarity was not observed for the CNTL group during exposure days, which was expected because panelists consumed yogurt at least once per week.

\section{Postexposure Session}

The results of the final session, including the mean values of acceptance, familiarity, and characteristic

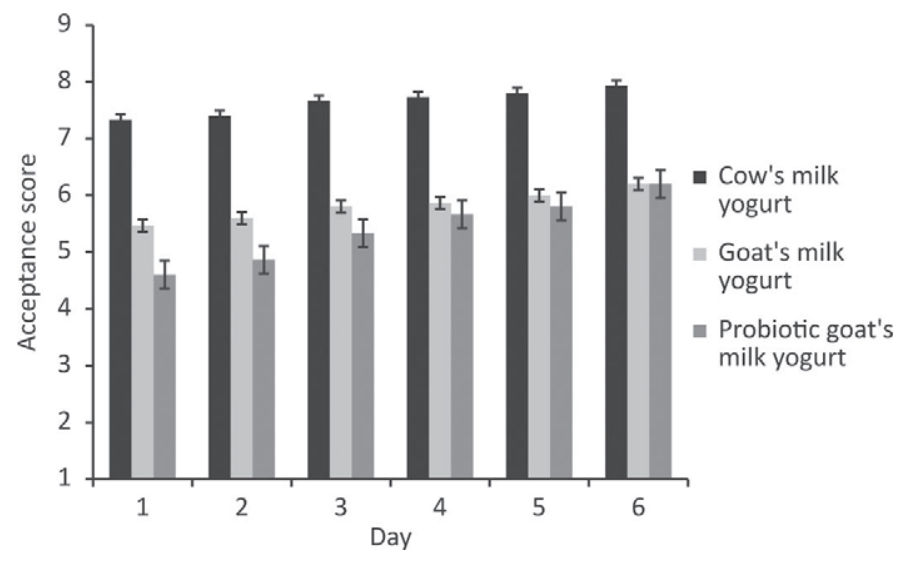

Figure 2. Means and standard deviations of acceptance scores for the yogurts during the repeated exposure in the study. "goaty" taste, are expressed in Table 2. Data were analyzed separately for each exposure group. Table 3 shows the comparison between acceptance and familiarity ratings for the first and the final sessions, in which acceptance and familiarity data from 45 panelists were grouped.

In relation to acceptance, no significant difference was observed for any treatments $(F=1.395$; $P=$ 0.259 ), even when data for each exposure group (Tables 2 and 3) were separated or when the final session was compared with the initial session (Table 3). Although not statistically significant, the CNTL group presented better product acceptance, scoring the product with the hedonic term "like moderately," whereas both EXP1 and EXP2 groups scored the product as "neither liked nor disliked." This fact shows that 6 sessions of exposure were not sufficient to increase the acceptance of goat milk yogurts. However, a correlation existed between the increased acceptance and the exposure days; thus, a greater exposure period could increase the acceptance of yogurt made from goat milk.

When a food is developed for children, its acceptance relies on its appearance, taste, and familiarity (Burgess-Champoux et al., 2006). In addition, Holmer et al. (2012) found that flavor was the main determinant factor of the overall liking, followed by texture, odor, and appearance. Children's preferences can be modified when they are repeatedly exposed to novel foods.

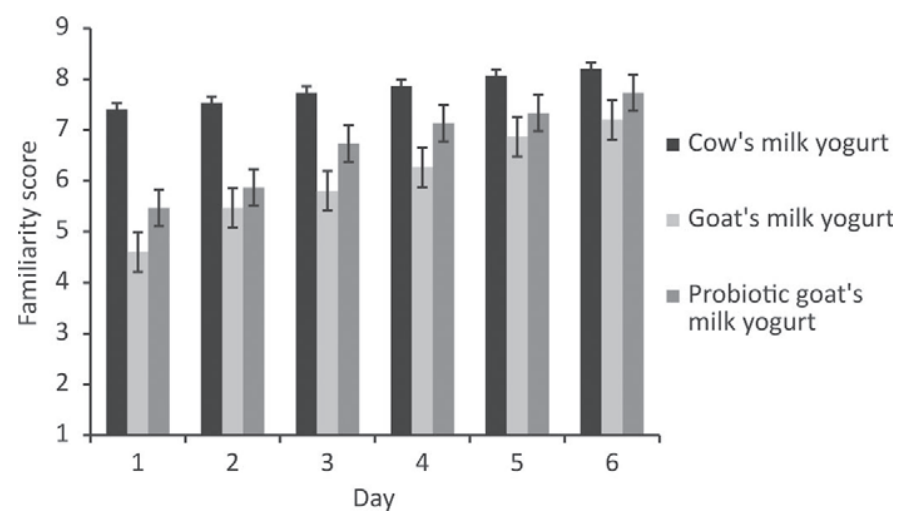

Figure 3. Means and standards deviation of familiarity scores for the yogurts during the repeated exposure in the study. 
Establishing the number of exposures required for preference learning depends on the exposure food sensory properties, such as its initial acceptance. Sometimes 10 or more exposures are needed for preference learning to take place (Liem and Graaf, 2004), and this number varies according to the tested product and target audience. This study used only $6 \mathrm{~d}$ because it was a rapidly repeated exposure. No information exists about this methodology application in dairy products and its application to adults.

The ratings of familiarity resulted in a significant overall increase of familiarity for both EXP1 and EXP2 groups, but not for the CNTL group. The result of CNTL group was not surprising, because it demonstrated the familiarity of the panelists for cow milk yogurt, and this trend was also observed by Methven et al. (2012). Table 2 shows a significant increase in the ratings of familiarity for the goat-milk-yogurt-exposure groups, regardless of the probiotics addition. As for the conventional goat milk yogurt, the mean scores were 5.333, 6.867, and 7.533 for CNTL, EXP1, and EXP2 groups, respectively. For the probiotic goat milk yogurt, the mean scores were 5.267, 6.733, and 7.333 for CNTL, EXP1, and EXP2 groups, respectively. These results show that $6 \mathrm{~d}$ of exposure were sufficient for increasing the consumers' familiarity with the product.

For the characteristic "goaty" taste, the mean scores obtained for the goat milk yogurt were 4.867 (CNTL), 5.000 (EXP1), and 5.533 (EXP2), whereas for the probiotic goat milk yogurt, these values were 4.267, 5.067, and 5.200, respectively. Thus, the panelists from both goat-milk-yogurt-exposure groups (EXP1 and EXP2) and CNTL group were indifferent to this attribute, as shown in Table 2. This distinctive taste is related to the presence of short-chain FA (caproic, caprylic, and capric acids), which have higher concentrations in the goat milk matrix (Park et al., 2007; Mayer and Fiechter, 2012). Surprisingly, this fact differs from reports in the literature (Martín-Diana et al., 2003; Mowlem, 2005; Slačanac et al., 2010; da Costa et al., 2013b), as consumers of these products tend to dislike this characteristic flavor, both in yogurts and other derivatives of this matrix.

The lower acceptance of fermented goat milk for consumers is in accordance with some studies (Martin-Diana et al., 2003; Mowlem, 2005; Slačanac et al., 2010), which demonstrated the need of new strategies to attract consumers, such as Brazilian consumers. Besides the repeated exposure, 2 other strategies can be used to improve the goat milk yogurt sensory performance. The first option is related to the development of yogurts made with skim milk, as the "goaty" taste comes from short- and medium-chain FA present in goat milk fat (Park et al., 2007) in dairy goat derivatives. Senaka
Ranadheera et al. (2012) verified that sensory acceptance of probiotic goat milk yogurts with added fruit pulp was low. However, their findings indicated that the overall liking of flavor of probiotic goat milk yogurt may be increased by fruit pulp addition to the product. Therefore, the second strategy to increase the sensory acceptance of fermented goat milk is the addition of fruit juice or pulp, or both, to dairy foods made from goat milk.

The home use test is an effective way to mimic actual food product consumption. However, it is not possible to ensure that respondents consume the full sample each day during the study period. In addition, the Brazilian population does not have the habit of consuming goat milk products in as large quantities as African and Asian consumers, mainly in the Middle East, where most products are traditionally made locally and elsewhere, and some have been industrially produced (Tamime et al., 2011). Therefore, consumers in the present study are not adapted to the peculiar "goaty" taste of goat milk yogurts.

However, our research presented interesting findings for the dairy industry, especially for goat milk processors. Even with just 6 sessions, which, at first glance can be considered few sessions, it is consistent and similar to recent studies published elsewhere. Indeed, the improvement of the liking for a regular food in a reduced-energy version and a snack and soup with intense sensory characteristics were reported using 5 sessions (Weijzen et al., 2008; O'Sullivan et al., 2010). Recently, 8 sessions were used to improve children's acceptance and familiarity of a low-sodium soup (Methven et al., 2012) and several types of fruits and vegetables (Osborne and Forestell, 2012).

In general, our study demonstrated that rapidly repeated exposure methodology could be used to improve consumer acceptance and familiarity of probiotic fermented goat milk. Further studies should cover more consumers and more repeated exposures should be performed. The use of consumer profiling techniques, such as the check-all-that-apply method, projective mapping, ultra flash profile and sorting (Cruz et al., 2013a; Santos et al., 2013), complete sensory profiling using quantitative descriptive analysis (Cadena et al., 2012; Kaaki et al., 2012; Albenzio et al., 2013; Cliff et al., 2013; Desai et al., 2013; Murtaza et al., 2013; Pimentel et al., 2013), and the investigation of the non-sensory factors, such as packaging design (Liem et al., 2012; Kim et al., 2013), should also be tools to understand consumer expectations and preferences.

\section{CONCLUSIONS}

Expectations for cow milk yogurt were high compared with goat milk yogurts. The indifferent expectations to 
goat products may be related to the unfamiliarity of Brazilian consumers with these products. For exposures sessions, although $6 \mathrm{~d}$ were sufficient to increase consumer familiarity with goat milk yogurts, this time was not enough to increase the acceptance of the products. Despite the additional probiotic flavor, acceptance was not increased. However, probiotic value was added to the goat milk yogurt. Increasing exposure sessions during the application of repeated-exposure methodology could be a future strategy to increase the acceptance of goat milk-based products, as a positive correlation between these parameters was observed.

\section{ACKNOWLEDGMENTS}

The authors are thankful for the financial support of the State of Rio de Janeiro Carlos Chagas Filho Research Foundation (FAPERJ, Rio de Janeiro, Brazil), process number E-26/103.003/2012. M. P. Costa and C. F. Balthazar were supported by the National Council of Technological and Scientific Development (CNPq, Brasília, Brazil).

\section{REFERENCES}

Albenzio, M., A. Campanozzi, M. D'Apolito, A. Santillo, M. Pettoello Mantovani, and A. Sevi. 2012. Differences in protein fraction from goat and cow milk and their role on cytokine production in children with cow's milk protein allergy. Small Rumin. Res. 105:202-205.

Albenzio, M., A. Santillo, M. Caroprese, A. Braghieri, A. Sevi, and F. Napolitano. 2013. Composition and sensory profiling of probiotic Scamorza ewe milk cheese. J. Dairy Sci. 96:2792-2800.

Anzman-Frasca, S., J. S. Savage, M. E. Marini, J. O. Fisher, and L. L. Birch. 2012. Repeated exposure and associative conditioning promote preschool children's liking of vegetables. Appetite 58:543-553.

AOAC International. 2005 Official Methods of Analysis. 18th ed. AOAC International, Gaithersburg, MD.

Ares, G., C. Barreiro, R. Deliza, A. Giménez, and A. Gámbaro. 2010. Consumer expectations and perception of chocolate milk desserts enriched with antioxidants. J. Sens. Stud. 25(Suppl. s1):243-260.

Bedani, R., E. A. Rossi, and S. M. I. Saad. 2013. Impact of inulin and okara on Lactobacillus acidophilus La-5 and Bifidobacterium animalis $\mathrm{Bb}-12$ viability in a fermented soy product and probiotic survival under in vitro simulated gastrointestinal conditions. Food Microbiol. 34:382-389.

Burgess-Champoux, T., L. Marquart, Z. Vickers, and M. Ricks. 2006. Perceptions of children parents and teachers regarding whole-grain foods and implications for a school-based intervention. J. Nutr. Educ. Behav. 38:230-237.

Cadena, R. S., A. G. Cruz, J. A. F. Faria, and H. M. A. Bolini. 2012. Reduced fat and sugar vanilla ice creams: Sensory profiling external preference mapping. J. Dairy Sci. 95:4842-4850.

Cardello, A. V. 2007. Measuring consumer expectations to improve food product development. Pages 223-261 in Consumer-Led Food Product Development. H. MacFie, ed. Woodhead Publishing Ltd., Cambridge, UK.

Cardello, A. V., and F. M. Sawyer. 1992. Effects of disconfirmed consumer expectations on food acceptability. J. Sens. Stud. 7:253277 .
Cardello, A. V., H. Schutz, C. Snow, and L. Lesher. 2000. Predictors of food acceptance, consumption and satisfaction in specific eating situations. Food Qual. Prefer. 11:201-216.

Castro, W. F., A. G. Cruz, M. S. Bisinotto, L. M. R. Guerreiro, J. A. F. Faria, H. M. A. Bolini, R. L. Cunha, and R. Deliza. 2013a. Development of probiotic dairy beverages: Rheological properties and application of mathematical models in sensory evaluation. J. Dairy Sci. 96:16-25.

Castro, W. F., A. G. Cruz, D. Rodrigues, G. Ghiselli, C. A. F. Oliveira, J. A. F. Faria, and H. T. Godoy. 2013b. Short communication: Effects of different whey concentrations on physicochemical characteristics and viable counts of starter bacteria in dairy beverage supplemented with probiotics. J. Dairy Sci. 96:96-100.

Cliff, M. A., L. Fan, K. Sanford, K. Stanich, C. Doucette, and N. Raymond. 2013. Descriptive analysis and early-stage consumer acceptance of yogurts fermented with carrot juice. J. Dairy Sci. 96:4160-4172.

Codex Alimentarius. 2010. Codex standard for fermented milks. 2nd ed. Codex standard 243-2003 in Codex Alimentarius: Milk and Milk Products. Codex Alimentarius Commission, Brussels, Belgium.

Costa, M. P., and C. A. Conte-Junior. 2013. Leites fermentados como alimentos funcionais. Animal Business Brasil 3:60-65.

Cruz, A. G., R. S. Cadena, W. F. Castro, E. A. Esmerino, J. B. Rodrigues, L. Gaze, J. A. F. Faria, M. Q. Freitas, R. Deliza, and H. M. A. Bolini. 2013a. Consumer perception of probiotic yogurt: Performance of check all that apply (CATA), projective mapping, sorting and intensity scale. Food Res. Int. 54:601-610.

Cruz, A. G., W. F. Castro, J. A. F. Faria, H. M. A. Bolini, R. M. S. Celeghini, R. S. L. Raices, C. A. F. Oliveira, M. Q. Freitas, C. A. Conte Júnior, and E. T. Mársico. 2013b. Stability of probiotic yogurt added with glucose oxidase in plastic materials with different permeability oxygen rates during the refrigerated storage. Food Res. Int. 51:723-728.

Cruz, A. G., W. F. Castro, J. A. F. Faria, P. C. B. Lollo, J. AmayaFarfán, M. Q. Freitas, and H. T. Godoy. 2012. Probiotic yogurts manufactured with increased glucose oxidase levels: Postacidification, proteolytic patterns, survival of probiotic microorganisms, production of organic acid and aroma compounds. J. Dairy Sci. 95:2261-2269.

da Costa, M. P., C. F. Balthazar, R. V. B. de Barros Pinto Moreira, A. Gomes da Cruz, and C. A. Conte Júnior. 2013a. Leite fermentado: Potencial alimento funcional. Enciclopédia Biosfera 9:1387-1408.

da Costa, M. P., H. L. A. da Silva, C. F. Balthazar, R. M. Franco, and M. A. S. Cortez. 2013b. Economic performance and sensory analysis of probiotic "Minas Frescal" cheese produced using bovine and caprine milk. Enciclopédia Biosfera 17:2306-2314.

Deliza, R., and H. J. MacFie. 1996. The generation of sensory expectation by external cues and its effect on sensory perception and hedonic ratings: A review. J. Sens. Stud. 11:103-128.

Desai, N. T., L. Shepard, and M. A. Drake. 2013. Sensory properties and drivers of liking for Greek yogurts. J. Dairy Sci. 96:74547466 .

Eissa, E. A., I. A. Mohamed Ahmed, A. E. A. Yagoub, and E. E. Babiker. 2010. Physicochemical, microbiological and sensory characteristics of yoghurt produced from goat milk. Livest. Res. Rural Develop. 22:137.

Ekinci, F. Y., and M. Gurel. 2008. Effect of using propionic acid bacteria as an adjunct culture in yogurt production. J. Dairy Sci. 91:892-899.

Fonseca, C. R., K. Bordin, A. M. Fernandes, C. E. C. Rodrigues, C. H. Corassin, A. G. Cruz, and C. A. F. Oliveira. 2013. Storage of refrigerated raw goat milk affecting the quality of whole milk powder. J. Dairy Sci. 96:4716-4724.

Gomes, A. A., S. P. Braga, A. G. Cruz, R. S. Cadena, P. C. B. Lollo, C. Carvalho, J. Amaya-Farfán, J. A. F. Faria, and H. M. A. Bolini. 2011. Effect of the inoculation level of Lactobacillus acidophilus in probiotic cheese on the physicochemical features and sensory performance compared with commercial cheeses. J. Dairy Sci. 94:4777-4786. 
Güler-Akın, M. B., and M. S. Akın. 2007. Effects of cysteine and different incubation temperatures on the microflora, chemical composition and sensory characteristics of bio-yogurt made from goat's milk. Food Chem. 100:788-793.

Holmer, A., H. Hausner, H. C. Reinbach, W. L. P. Bredie, and K. Wendin. 2012. Acceptance of Nordic snack bars in children aged 8-11 years. Food Nutr. Res. 56:10484. http://dx.doi.org/10.3402/ fnr.v56i0.10484.

Kaaki, D., O. Kebbe Baghdadi, N. E. Najm, and A. Olabi. 2012. Preference mapping of commercial Labneh (strained yogurt) products in the Lebanese market. J. Dairy Sci. 95:521-532.

Kim, M. K., K. Lopetcharat, and M. A. Drake. 2013. Influence of packaging information on consumer liking of chocolate milk. J. Dairy Sci. 96:4843-4856.

Kinnear, M., and H. L. de Kock. 2011. Would repeated consumption of sports drinks with different acidulants lead to hedonic adjustment? Food Qual. Prefer. 22:340-345.

Lakkakula, A., J. Geaghan, M. Zanovec, S. Pierce, and G. Tuuri. 2010 Repeated taste exposure increases liking for vegetables by lowincome elementary school children. Appetite 55:226-231.

Liem, D. G., and C. de Graaf. 2004. Sweet and sour preferences in young children and adults: Role of repeated exposure. Physiol. Behav. 83:421-429.

Liem, D. G., F. Miremadi, E. H. Zandstra, and R. S. J. Keast. 2012. Health labelling can influence taste perception and use of table salt for reduced-sodium products. Public Health Nutr. 15:2340-2347. http://dx.doi.org/10.1017/S136898001200064X.

Liem, D. G., N. Toraman Aydin, and E. H. Zandstra. 2012. Effects of health labels on expected and actual taste perception of soup. Food Qual. Prefer. 25:192-197.

MacFie, H. J., N. Bratchell, K. Greenhoff, and L. V. Vallis. 1989. Designs to balance the effect of order of presentation and first-order carry-over effects in hall tests. J. Sens. Stud. 4:129-148.

Martín-Diana, A., C. Janer, C. Peláez, and T. Requena. 2003. Development of a fermented goat's milk containing probiotic bacteria. Int. Dairy J. 13:827-833.

Masamba, K. G., and L. Ali. 2013. Sensory quality evaluation and acceptability determination of yoghurt made from cow, goat and soy milk. Afr. J. Food Sci. Technol. 4:44-47.

Mayer, H. K., and G. Fiechter. 2012. Physical and chemical characteristics of sheep and goat milk in Austria. Int. Dairy J. 24:57-63.

Methven, L., E. Langreney, and J. Prescott. 2012. Changes in liking for a no added salt soup as a function of exposure. Food Qual. Prefer. 26:135-140.

Mowlem, A. 2005. Marketing goat dairy produce in the UK. Small Rumin. Res. 60:207-213.

Murtaza, M. A., S. U. Rehman, F. M. Anjum, and N. Huma. 2013. Descriptive sensory profile of cow and buffalo milk Cheddar cheese prepared using indigenous cultures. J. Dairy Sci. 96:1380-1386.
O'Sullivan, H. L., E. Alexander, D. Ferriday, and J. M. Brunstrom. 2010. Effects of repeated exposure on liking for a reduced-energydense food. Am. J. Clin. Nutr. 91:1584-1589.

Oelschlaeger, T. A. 2010. Mechanisms of probiotic actions-A review. Int. J. Med. Microbiol. 300:57-62.

Osborne, C. L., and C. A. Forestell. 2012. Increasing children's consumption of fruit and vegetables: Does the type of exposure matter? Physiol. Behav. 106:362-368.

Park, Y. W., M. Juárez, M. Ramos, and G. F. W. Haenlein. 2007. Physico-chemical characteristics of goat and sheep milk. Small Rumin. Res. 68:88-113.

Pimentel, T. C., A. G. Cruz, and S. H. Prudencio. 2013. Influence of long-chain inulin and Lactobacillus paracasei subspecies paracasei on the sensory profile and acceptance of a traditional yogurt. J. Dairy Sci. 96:6233-6241.

Sanders, M. E. 2009. How do we know when something called "probiotic" is really a probiotic? A guideline for consumers and health care professionals. Funct. Food Rev. 1:3-12.

Santos, B. A., M. A. R. Pollonio, A. G. Cruz, V. C. Messias, R. A Monteiro, J. A. F. Faria, M. Q. Freitas, and H. M. A. Bolini. 2013. Ultra-flash profile and projective mapping for describing sensory attributes of prebiotic mortadellas. Food Res. Int. 54:1705-1711.

Senaka Ranadheera, C., C. A. Evans, M. C. Adams, and S. K. Baines. 2012. Probiotic viability and physico-chemical and sensory properties of plain and stirred fruit yogurts made from goat's milk. Food Chem. 135:1411-1418.

Slačanac, V., R. Božanić, J. Hardi, J. Rezessyné Szabó, M. Lučan, and V. Krstanović. 2010. Nutritional and therapeutic value of fermented caprine milk. Int. J. Dairy Technol. 63:171-189.

Stolzenbach, S., W. L. P. Bredie, R. H. B. Christensen, and D. V. Byrne. 2013. Impact of product information and repeated exposure on consumer liking, sensory perception and concept associations of local apple juice. Food Res. Int. 52:91-98.

Tamime, A. Y., M. Wszolek, R. Božanić, and B. Özer. 2011. Popular ovine and caprine fermented milks. Small Rumin. Res. 101:2-16.

Vinderola, C. G., N. Bailo, and J. A. Reinheimer. 2000. Survival of probiotic microflora in Argentinian yoghurts during refrigerated storage. Food Res. Int. 33:97-102.

Wang, S., H. Zhu, C. Lu, Z. Kang, Y. Luo, L. Feng, and X. Lu. 2012 Fermented milk supplemented with probiotics and prebiotics can effectively alter the intestinal microbiota and immunity of host animals. J. Dairy Sci. 95:4813-4822.

Weijzen, P. L. G., D. G. Liem, E. H. Zandstra, and C. de Graaf. 2008 Sensory specific satiety and intake: The difference between nibbleand bar-size snacks. Appetite 50:435-442.

Williams, K. E., C. Paul, B. Pizzo, and K. Riegel. 2008. Practice does make perfect. A longitudinal look at repeated taste exposure. Appetite $51: 739-742$ 